\title{
Effects of Extreme Pressure Additives on Lubricity and Anti-seizure Property of Lubricants
}

\author{
Seog-Young HAN and Joon-Jeong $\mathrm{YI}^{11}$
}

Department of Mechanical Engineering, The Hanyang University, Seongdong-Gu, Seoul, 133-791 Korea.

1) Research Institute of Industrial Science and Technology, Rolling Process R \& E Team, Hyoja-Dong, Pohang, 790-600 Korea.

(Received on October 7, 1996; accepted in final form on January 14, 1997)

\begin{abstract}
The effects on lubricity and anti-seizure property of lubricants according to base oils and EP additives of sulfur and phosphorous types in cold rolling were evaluated by a laboratory scale rolling mill, where the contact conditions between work roll and strip are very close to an actual cold rolling mill. The following experimental results were obtained. Sulfur type EP additive improves lubricity better than phosphorous type. In contrast, phosphorous type EP additive improves anti-seizure property better than sulfur type. And anti-seizure property is not affected by the kinds of base oil, but improved by the kinds and the amount of EP additives. Therefore, the amount of EP additives of sulfur and phosphorous types must be controlled in order to improve both lubricity and anti-seizure property. In addition, the existence of EP film was verified from the results of EDS analysis of the Falex test pins.
\end{abstract}

KEY WORDS: lubricity; anti-seizure property; lubricant; cold rolling; extreme pressure additives; extreme pressure film.

\section{Introduction}

As the necessity of high speed and high reduction ratio rolling for improvement of productivity has been gathered strength from the latter half of 1970's, highproduction cold rolling is commonly conducted on tandem cold mill in the steel industry. ${ }^{1)}$ In these circumstances, a surface defect which is called as heat scratch, friction pick up or heat streak, easily occurs on the surfaces of strip and/or work roll. ${ }^{2)}$

The occurrence of heat scratch is one of the critical causes of quality deterioration of strip surfaces, the lowering of operation efficiency, and the increase of work roll exchange period at high speed rolling. Also it is one of the direct causes ${ }^{3,4)}$ to limit reduction ratio and rolling speed which becomes lower than the designed maximum rolling speed at actual cold rolling. Furthermore, the economical efficiency of rolling oil becomes another problem because the emulsion of high concentration should be used for high speed cold rolling in order to give high lubricity. As mentioned above, as rolling speed is limited by the properties of rolling oil, the improvement and the development of a cold rolling oil suitable for high speed and high reduction rolling conditions is urgently needed in order to response to the trend of high speed rolling and ultra thin strip. ${ }^{5 \text { ) }}$

In this study, the influences of base oils and extreme pressure (in below: EP) additives on lubricity and antiseizure property of cold rolling oils were investigated. This study was carried out with estimation experiments of lubricity and anti-seizure property using a laboratory scale mill, where the lubrication situation between strip and work roll was very similar to an actual cold mill, in contrast to experimental conditions ${ }^{6}$ by labroatory instruments such as the Soda type pendulum friction coefficient tester, the Falex tester, and the four ball tester, etc. The schematic diagram and specifications of a laboratory scale mill are shown in Fig. 1 and Table 1, respectively. Also, EDS (energy dispersive spectrometer) and ESCA (electron spectroscopy for chemical analysis) were applied in order to confirm the existence of EP film by a chemical reaction between strip surface and rolling oil.

\section{Selection of Samples}

The test lubricants were classified into three catagories; base oils, fatty acids, and EP additives. The following base oils were selected; tallow, lard, palm oil, pentaerythritol ester of the hindered ester group, and trimethylol-propane oleate. The following fatty acids were used; tallow fatty acid, oleic acid, and dimer acid. The used EP additives were an adduct of alkyl phosphate ethylene oxide and amine phosphate in phosphorous-type (p-type), sulfurized animal fat and poly alkyl sulfide in sulfur-type (s-type), and zinc dithio-dialkyl-phosphate ${ }^{7)}$ in mixed (sulfur and phosphorous)-types.

Friction coefficients and the degree of load capacity were measured for each test materials at various temperatures using the Soda type pendulum friction coefficient tester and the Falex tester. From the results, some of the test materials which showed smaller friction 
coefficients and smaller changes of them in various temperatures were selected for formulating test rolling oils, considering high speed rolling conditions such as

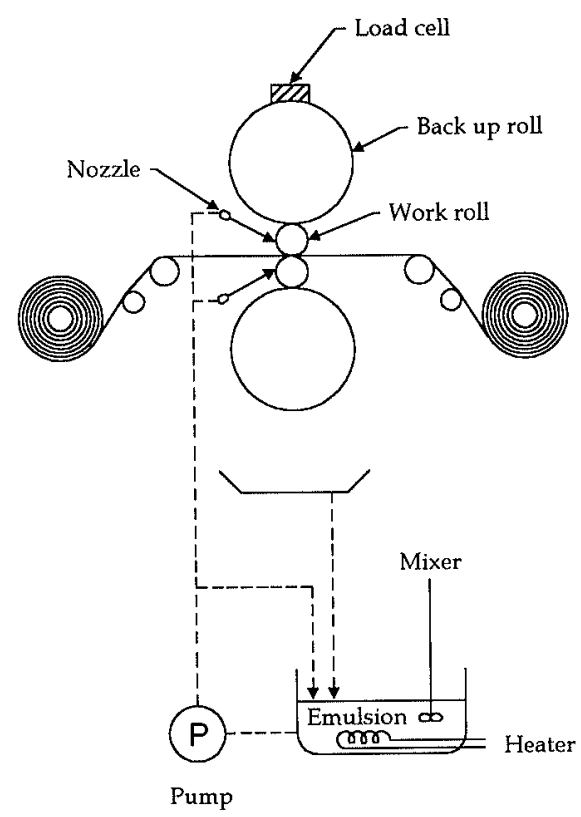

Fig. 1. Schematic diagram of a laboratory scale mill.

Table 1. The specification of a laboratory scale mill.

\begin{tabular}{ll}
\hline \multicolumn{1}{c}{ Mill type } & $4 \mathrm{Hi}$ reverse mill \\
\hline Max. rolling force & $2.94 \mathrm{MN}$ \\
Max. tension & $39200 \mathrm{~N}$ \\
Max. rolling speed & $200 \mathrm{mpm}$ \\
Work roll. dia. & $100 \mathrm{~mm}, 200 \mathrm{~mm}$ \\
Work roll barrel & $470 \mathrm{~mm}$ \\
Coil specification & \\
$\quad$ Inside dia. & $508.6 \mathrm{~mm}$ \\
Max. outside dia. & $1250 \mathrm{~mm}$ \\
Max. coil weight & $19600 \mathrm{~N}$ \\
Max. strip width & $350 \mathrm{~mm}$ \\
Max. strip thickness & $5 \mathrm{~mm}$ \\
Lubrication system & \\
Type & Recirculation \\
Tank capacity & $3000 \mathrm{l}$ \\
Max. spray capacity & $250 \mathrm{l} / \mathrm{min}$ \\
Temperature & $30-60^{\circ} \mathrm{C}$ \\
Speed of revolution of agitator & $1800 \mathrm{rpm}$ \\
\hline
\end{tabular}

rolling speed, reduction ratio and strip temperature. Nine test rolling oils were formulated with the selected test materials in order to investigate the influence of base oils and EP additives on lubricity and anti-seizure property. The basic properties of test rolling oils are shown in Table 2.

\section{Experimental Method}

\subsection{Experimental Method of Lubricity Estimation}

The experiment of lubricity estimation was carried out under the rolling conditions shown in Table 3 by use of work roll of $200 \mathrm{~mm}$ diameter. Strip was rolled repeatedly until it reaches the reduction ratio of $90 \%$ and then the change in friction coefficients according to the pass number was compared with each other. When the reduction ratio became higher than $90 \%$, the change of strip thickness became very small because of the flattening of work roll, and thus it was difficult to compare friction coefficients of test rolling oils. The steady-state friction coefficients were determined by the roll force method ${ }^{8)}$ based on the thickness measured at the end of each roll pass. The roll force equation derived by Bland and Ford ${ }^{9)}$ is as follows and the model of Bland and Ford's roll force calculation is shown in Fig. 2.

$$
\begin{aligned}
& P=R^{\prime}\left(\int_{0}^{\theta_{\mathrm{n}}} p^{+} d \theta+\int_{\theta_{\mathrm{n}}}^{a} p^{-} d \theta\right) \\
& p^{+}=k h / h_{2}\left(1-s_{2} / k_{2}\right) \exp (\mu H) \\
& p^{-}=k h / h_{1}\left(1-s_{1} / k_{1}\right) \exp \mu\left(H_{1}-H\right) \\
& H=2\left(R^{\prime} / h_{2}\right)^{1 / 2} \tan ^{-1}\left(R^{\prime} / h_{2} \theta\right)^{1 / 2}
\end{aligned}
$$

where, $P$ : total normal pressure distribution per unit width,

$p^{+}:$normal pressure distribution in the arc of contact, between the neutral plane and the exit plane,

$p^{-}$: normal pressure distribution in the arc of contact, between the entry plane and the neutral plane,

$R^{\prime}$ : radius of flattened work roll,

\begin{tabular}{|c|c|c|c|c|c|c|c|c|c|c|}
\hline Compositions & $\mathrm{RT}-1$ & RT-2 & $\mathrm{RT}-3$ & RT-4 & RT-5 & RT-6 & $\mathrm{RT}-7$ & RT-8 & RT-9 & Remarks \\
\hline Tallow & 92 & 45.5 & 86.5 & 81.5 & 90.5 & 85.5 & 85.5 & 80.5 & 45 & (unit: wt $\%$ ) \\
\hline Synthetic oil & & 45.5 & & & & & & & 45 & \\
\hline Fatty acid & 2 & 2 & 2 & 2 & 2 & 2 & 2 & 2 & 2 & \\
\hline Phosphorous-type EP A & & & & & 2.5 & 4.5 & 2.5 & 2.5 & 2.5 & \\
\hline Phosphorous-type EP B & & & & & 2.5 & 5.5 & 2.5 & 2.5 & 2.5 & \\
\hline Sulfur-type EP & & & 5 & 10 & & & 5 & 10 & & \\
\hline Particle size $(\mu)$ & 6.0 & 6.0 & 6.0 & 6.0 & 6.0 & 6.0 & 6.0 & 6.0 & 6.0 & after $5 \mathrm{~min}$ at \\
\hline ESI-30 & 82 & 82 & 77 & 82 & 59 & 67 & 68 & 73 & 72 & $10000 \mathrm{rpm}$ \\
\hline $\mathrm{pH}(\times 25)$ & 6.5 & 6.4 & 6.5 & 6.5 & 2.7 & 2.2 & 2.7 & 2.7 & 2.7 & \\
\hline Specific weight $\left(60^{\circ} \mathrm{C}\right)$ & 0.886 & 0.893 & 0.892 & 0.895 & 0.887 & 0.891 & 0.891 & 0.895 & 0.898 & \\
\hline Viscosity $(\mathrm{cSt})\left(40^{\circ} \mathrm{C}\right)$ & 31 & 43 & 32 & 32 & 33 & 35 & 33 & 34 & $47^{\circ}$ & \\
\hline AV & 9.06 & 9.04 & 9.9 & 10.0 & 15.7 & 21.4 & 15.3 & 15.2 & 15.8 & \\
\hline SV & 194 & 193 & 198 & 201 & 201 & 194 & 199 & 201 & 195 & \\
\hline
\end{tabular}

$k_{1}, k_{2}$ : yield stresses at the entry and exit points, respectively,

Table 2. Compositions and properties of test rolling oils. 
Table 3. Rolling conditions of experiment of lubricity estimation.

\begin{tabular}{ll}
\hline Strip & $\mathrm{SPCC} 2.2 \mathrm{~mm} \cdot 145 \mathrm{~mm} \cdot$ coil \\
Rolling load & $980 \mathrm{kN}$ \\
Rolling speed & $30 \mathrm{mpm}$ \\
Forward tension & Deformation resistance for entry \\
Backward tension & $25 \%$ of deformation resistance for strip \\
& thickness per pass \\
Rolling oil & $120 \mathrm{l} / \mathrm{min}$ \\
& $5 \mathrm{wt} \%, 50-55^{\circ} \mathrm{C}$ \\
\hline
\end{tabular}

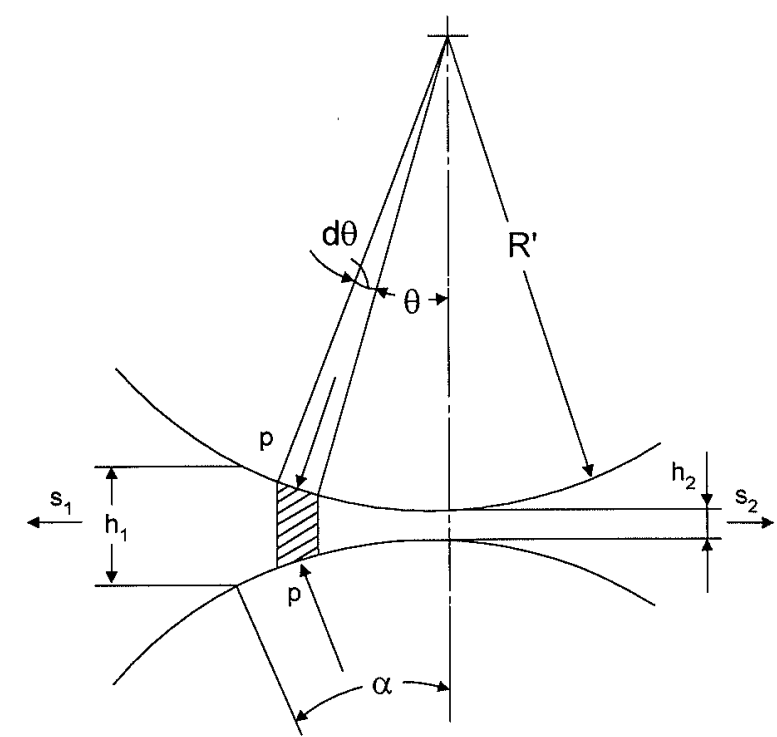

Fig. 2. The model of Bland and Ford's roll force calculation.

$h_{1}, h_{2}$ : strip thickness at the entry and exit points, respectively,

$k$ : yield stress at any point in the arc of contact,

$\mu$ : friction coefficient between strip and work roll,

$H_{1}$ : value of $H$ at the entry $(\theta=\alpha)$,

$\alpha$ : roll bite angle, and

$\theta_{\mathrm{n}}$ : neutral angle.

$p^{+}$and $p^{-}$are expressed as the functions of the friction coefficient, the exit and entry strip thickness, and the variable parameter $\theta$ on the arc of contact. The injection angle was controlled in order to inject the rolling oil on the contact line between work roll and trip shown in Fig. 3(a), and rolling oil was supplied by all the 10 nozzles of the rolling oil head.

\subsection{Experimental Method of Anti-seizure Property Estimation}

The experiment of anti-seizure estimation was carried out under the rolling conditions shown in Table 4. The work roll of $100 \mathrm{~mm}$ diameter was used for reducing rolling time and rolling speed to be required for the occurrence of heat scratches comparing with the case of the work roll of $200 \mathrm{~mm}$ diameter. Strip was rolled for $3 \mathrm{~min}$, and cooled in air for $2 \mathrm{~min}$ in order to make heat scratch at least at the rolling speed $60 \mathrm{mpm}$ (meters per minute) considering the maximum coil weight of the laboratory scale mill. Rolling oil was supplied by only one nozzle at the center out of the 10 nozzles of the rolling oil head, and by two nozzles at the end of the rolling oil head were used for by-pass purposes, and the

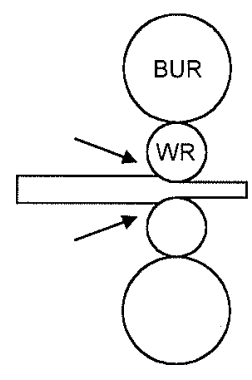

(a)

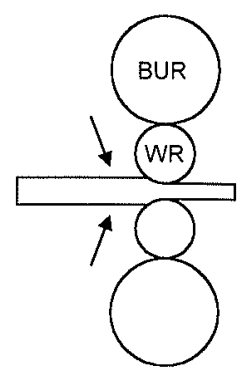

(b)
Fig. 3. The injection angle of rolling oil for (a) lubricity estimation. (b) anti-seizure estimation.

Table 4. Rolling conditions of experiment of anti-seizure property estimation.

$\begin{array}{ll}\text { Strip } & \text { SPCC } 2.2 \mathrm{~mm} \cdot 145 \mathrm{~mm} \cdot \text { coil } \\ \text { Reduction ratio } & 50 \% \\ \text { Rolling speed } & 10,20,30,40,50,60 \mathrm{mpm} \\ \text { Forward tension } & 31 \mathrm{kN} \\ \text { Backward tension } & 6 \mathrm{kN} \\ \text { Rolling oil } & 1.9 / / \mathrm{min} \text { per nozzle } \\ & 5 \mathrm{wt} \%, 50-55^{\circ} \mathrm{C}\end{array}$

remaining 7 nozzles were sealed up. The injection direction of the rolling oil was controlled by adjustable joints in order to inject it on the strip surface only to increase the temperature of work roll, as shown in Fig. 3(b). After the rolling, specimens were collected from the end part at each rolling speed, and then investigated by an optical microscope.

\subsection{Observation of Existence of Extreme Pressure Film}

Many experimental studies ${ }^{10,11)}$ reported that rolling oils included EP additives showed better effect on lubricity and anti-seizure property due to EP film formed on the strip surface by a chemical reaction between EP additives and strip. But rolling oils used in their studies were only undiluted pure oils and it has not been reported that EP film was found from specimens rolled with 3-5 wt $\%$ emulsion as in actual cold rolling process.

Therefore, in order to investigate the possible existence of the EP film in the case of pure rolling oil as in previous studies, the Falex test pins used for measuring the degree of load capacity were examined. And in the case of $5 \mathrm{wt} \%$ emulsion as in actual cold rolling process, the specimen collected from the first and the last pass in the experiment of lubricity estimation and the specimen collected at 40 , 50 and $60 \mathrm{mpm}$ in the experiment of anti-seizure property estimation were examined. As the methods of surface analysis, EDS (energy dispersive spectrometer) and ESCA (electron spectroscopy for chemical analysis) were applied to both the worn surfaces of the Falex test pins and the specimen.

\section{Results and Discussion}

The estimation of lubricity was based upon the steady-state friction coefficient of each rolling pass, which was calculated by the roll force equation derived by Bland and Ford. ${ }^{9)}$ In this study, as friction coefficient was smaller, lubricity was estimated better. Since the experi- 
ment results showed that reduction ratios for the first, second, third and fourth pass reached 56-70, 76-84, 85-89 and 90-91\%, respectively, estimation of lubricity was carried out by comparing friction coefficients mainly for the first and second pass, and then for the third and the fourth pass. It is deduced that flattening deformation is not servere until the second pass.

\subsection{Effect of Base Oils and EP Additives on Lubricity}

In order to investigate the effect of the kinds of base oils on lubricity, RT-1 and RT-2 were compared. It was found that RT-2 showed a better effect than RT-1, in other words, synthetic oil showed a better effect than tallow as shown in Fig. 4. It is deduced that synthetic oil has a higher viscosity index and a higher viscosity than tallow, so that the property of plate out in rolling process becomes improved.

Next, in order to investigate the effects of EP additives, RT -9 composed of synthetic oil and p-type EP additives was compared with RT-2. Also RT-3, RT-4, RT-5, RT-6, RT-7, and RT-8 composed of tallow and p- or s-type EP additives were compared with RT-1. The results of experiment indicated that RT-9 showed a better lubricity than RT-2, and that RT-3, RT-4, RT-5, RT-6, RT-7, and RT-8 showed a better lubricity than RT-1. It was thought that lubricity of rolling oils including EP additives may have been improved by an EP film formulated by a chemical reaction between EP additives and strip surface. ${ }^{11)}$ The results were summarized as follows and the comparison graphs of friction coefficient for RT-1, RT-2 and RT-9, and for RT-1, RT-3, RT-5 and RT-7 typically were depicted in Figs. 4 and 5, respectively.

$$
\text { RT-9 }>\text { RT-2 }>\text { RT-1 }
$$

RT-3, RT-4, RT-5, RT-6, RT-7, RT-8>RT-1

In order to examine the effect of the amount of p-type EP additives on lubricity, RT-5 was compared with RT-6, and of s-type EP additive, RT-3 was compared with RT-4. From the results of the experiment, RT-6 and RT-4 showed a better effect on lubricity than RT-5 and

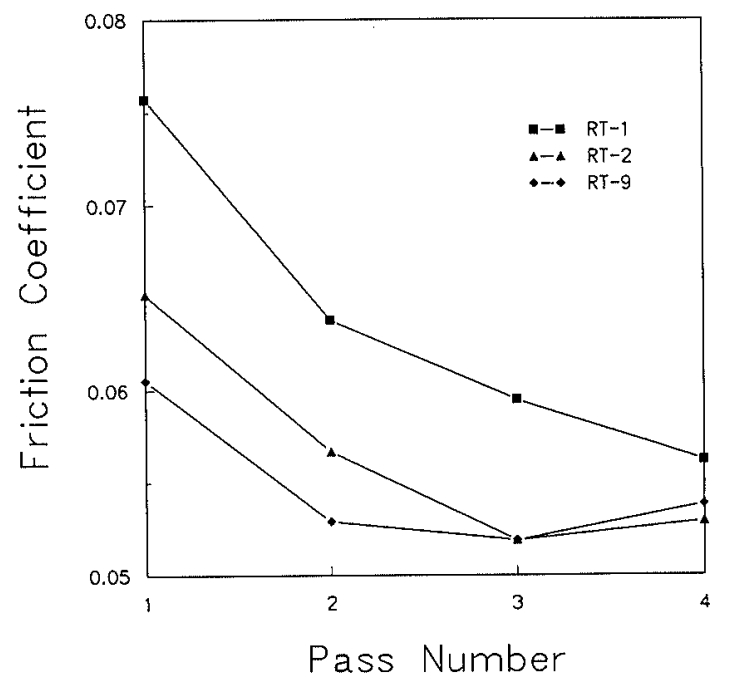

Fig. 4. Comparison of friction coefficient for RT-1, RT-2 and RT-9.
RT-3, respectively. It was found that increasing amount of EP additives, whether p- or s-type EP additives, gave a better effect on lubricity. The results were summarized as follows.

$$
\begin{aligned}
& \text { RT-6>RT-5 } \\
& \text { RT-4 > RT-3 }
\end{aligned}
$$

In order to examine what type of EP additives give better effect on lubricity in the case of the same amount of EP additives, RT-3 composed of s-type EP additive was compared with RT-5 composed of p-type EP additives, and also RT-4 composed of s-type EP additive was compared with RT-6 composed of p-type EP additives, respectively. From the experiment it was found that s-type EP additive showed a better effect than p-type EP additives when their amount was the same. This result was consistent with Sakurai's result ${ }^{10}$ that the degree of load capacity for test oils with s-type EP additives increased that those with p-type EP additives under the EP state. The results were summarized as follows, and the comparison graphs of friction coefficient for RT-3,

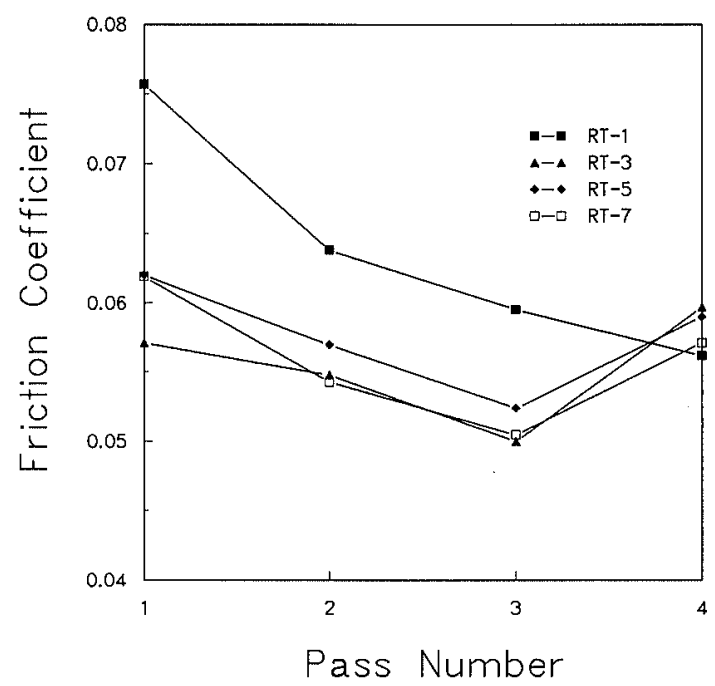

Fig. 5. Comparison of friction coefficient for RT-1, RT-3, RT-5 and RT-7.

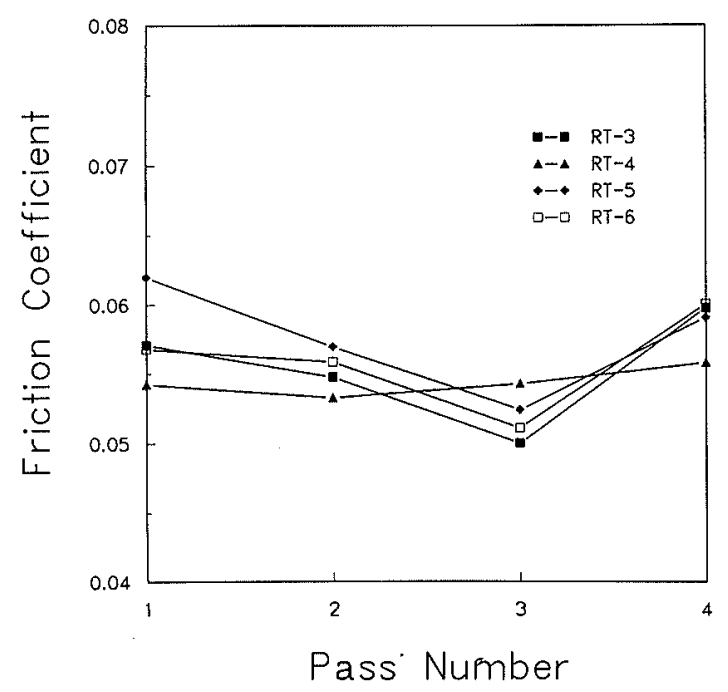

Fig. 6. Comparison of friction coefficient for RT:3, RT-4, RT-5 and RT6. 
RT-4, RT-5 and RT-6 are shown in Fig. 6.

$$
\begin{aligned}
& \text { RT-3 > RT -5 } \\
& \text { RT-4>RT-6 }
\end{aligned}
$$

In order to investigate the effects of mixed-type EP additives, RT-7 was compared with RT-3, and RT-5 and RT-8 were compared with RT-4 and RT-5, respectively. From the results, RT-7, which is the case where the amount of mixed-type EP additives was less than or equal to $10 \mathrm{wt} \%$, showed intermediate lubricity between RT-3 and RT-5, and RT-8, which is the case of the amount of mixed-type EP additives was greater than $10 \mathrm{wt} \%$, showed less lubricity than both RT-4 and RT-5. That is, increase of the total amount of EP additives does not mean improvement of lubricity. It was understood that if the amount of mixed-type EP additives was over a certain limit, lubricity was conversely reduced by a chemical reaction of the two types of EP additives. This result is consistent with Kawamura's study. ${ }^{12)}$ These results are shown in Figs. 5 and 7, respectively.

$$
\begin{aligned}
& \text { RT-3>RT-7>RT-5 } \\
& \text { RT-4>RT-5>RT-8 }
\end{aligned}
$$

From the experiment of lubricity estimation for RT-1 to RT-9, the following results were obtained, and the lubricity comparison graph of RT-3 and RT-4 of the test rolling oils having the best lubricity, and RT-2 and RT- 8 of test rolling oils having the worst lubricity is depicted in Fig. 8.

$$
\begin{aligned}
& \text { RT }-4>\text { RT }-3>\text { RT }-6 \cong \text { RT }-9 \\
& \cong \text { RT }-7>\text { RT }-5>\text { RT }-2>\text { RT }-8>\text { RT }-1
\end{aligned}
$$

\subsection{Effect of Base Oils and EP Additives on Anti-seizure Property}

In order to examine the effects of base oils and EP additives on anti-seizure property, four kinds of test rolling oils, i.e. RT-3, RT-5, RT-7, and RT-9 were chosen and then estimation experiments for anti-seizure property were carried out. The results were obtained as shown in Table 5. The summary of the results is as follows.

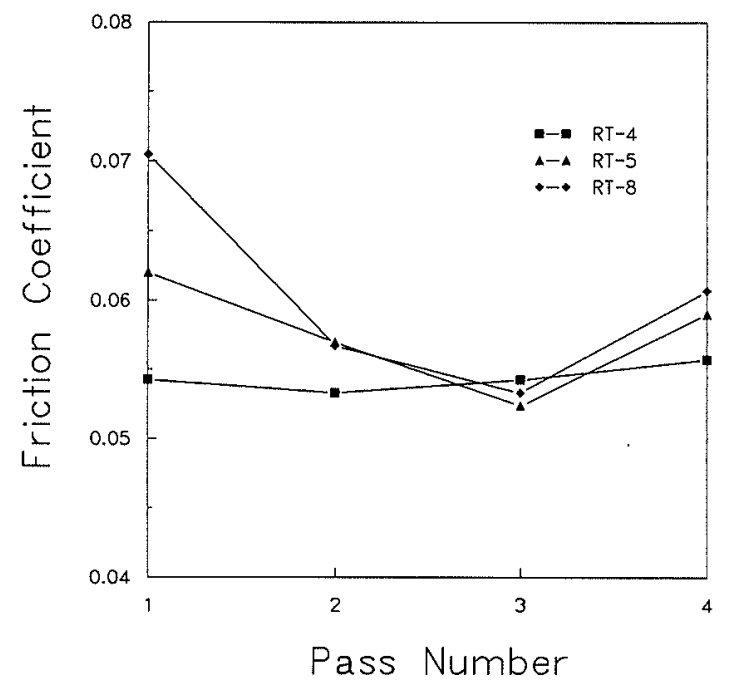

Fig. 7. Comparison of friction coefficient for RT-4, RT-5 and RT-8.

\section{RT $-5 \cong \mathrm{RT}-9>\mathrm{RT}-7>\mathrm{RT}-3$}

From the comparison of RT-5 and RT-9, it was found that anti-seizure property was not relavant with the kind of base oils, whether tallow or synthetic oil, but with the kinds and the amount of EP additives. And from the comparison of RT-3 and RT-5, it was found that p-type EP additive was more effective than s-type EP additive on anti-seizure property. This is the contrary to the result of lubricity estimation. Also RT-7, composed of mixedtype EP additives showed intermediate anti-seizure property between RT-3 and RT-5, composed of only s-type and p-type EP additives, respectively. It was thought that anti-seizure property became conversely reduced due to a chemical reaction between the two types of EP additives. Therefore, the amount of s- and p-type EP additives must be controlled in order to improve both lubricity and anti-seizure property.

\subsection{Observation Result of Existence of Extreme Pres- sure Film}

From the results of EDS analysis using the Falex test pins for RT-3 to RT-9 including EP additives, S peak for RT-3 and RT-4, P peak for RT-5, RT-6 and RT-9, and both $\mathrm{P}$ and $\mathrm{S}$ peaks for RT-7 and RT-8 were found. The results of EDS analysis for RT-4, RT-6 and RT-8 are shown in Fig. 9. And from the results of EDS analysis using the specimen collected from the first and last pass in the experiment of lubricity estimation and specimen at 40,50 and $60 \mathrm{mpm}$ in the experiment of anti-seizure estimation, there was not found any $\mathrm{P}$ or $\mathrm{S}$ peak. By

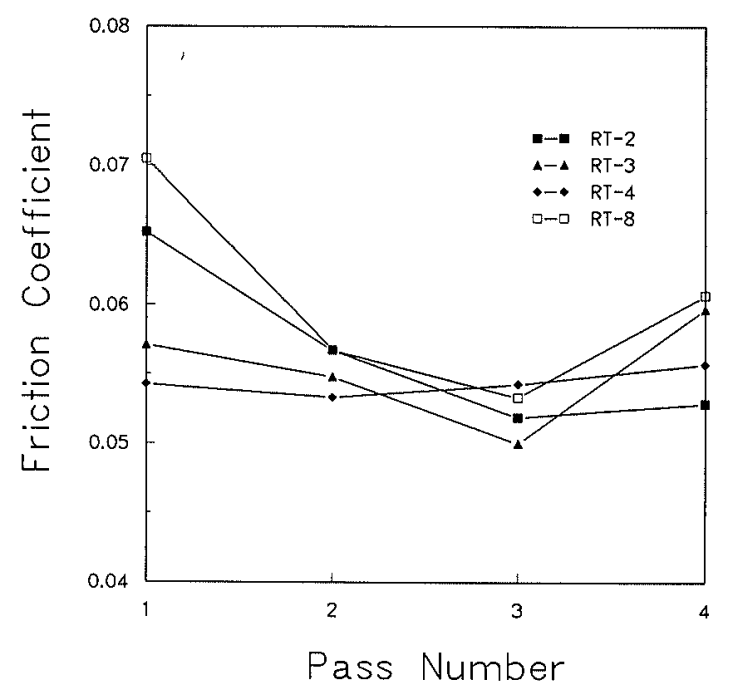

Fig. 8. Comparison of friction coefficient for RT-2, RT-3, RT-4 and RT-8.

Table 5. The results of anti-seizure property estimation.

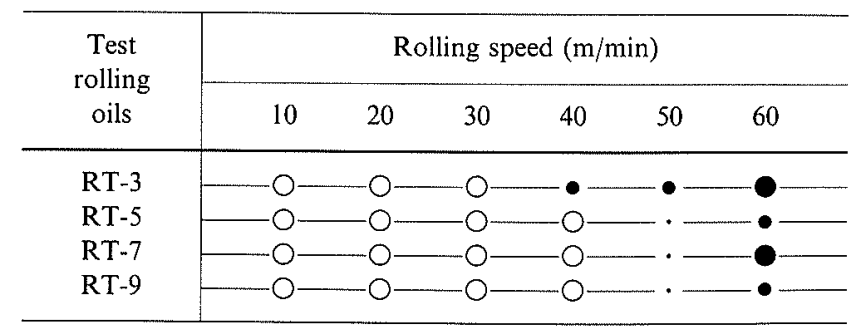

heat scratch not occurred. $-\bullet$ heat scratch occurred. 

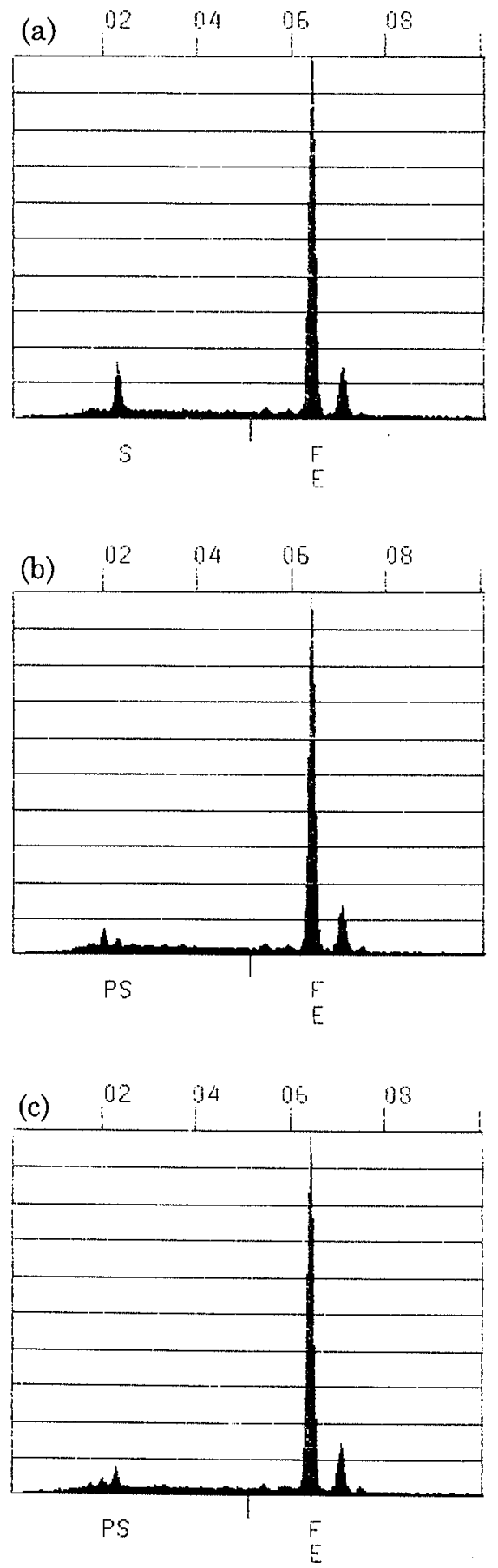

Fig. 9. The results of EDS analysis of the Falex test pins for (a) RT-4, (b) RT-6, (c) RT-8.

considering that EP film might have been too thin to detect, ESCA was then carried out for the specimen. But there was not found any peak of $\mathrm{P}$ or $\mathrm{S}$ auger peak, either.

From the above results, the existence of the EP film formed by a chemical reaction between EP additives of the test rolling oils and the worn surfaces of the Falex test pins was verified in the pure test rolling oils, but it was impossible to verify the existence of the EP film in $5 \mathrm{wt} \%$ emulsion. It was thought that since the amount of the EP additives of the test rolling oils was very small and that it became too much small amount in the $5 \mathrm{wt} \%$ emulsion, EP film might have not been found even though it existed.

\section{Conclusions}

The effects on lubricity and anti-seizure property of lubricants according to the base oils and the EP additives of s- and p-types in cold rolling were evaluated by a laboratory scale rolling mill, where the contact conditions between work roll and strip are very close to an actual cold rolling mill. The experimental results were obtained as follows;

(1) S-type EP additives have better effects on lubricity than p-type EP additives.

(2) Anti-seizure property is not affected by the kinds of base oil, but improved by the kinds and the amount of $\mathrm{EP}$ additives.

(3) P-type EP additives have better effects on anti-seizure property than s-type EP additives.

(4) The amount of s- and p-type EP additives must controlled in order to improve both lubricity and antiseizure property.

(5) The existence of EP film was verified from the results of EDS analysis of the Falex test pins.

\section{REFERENCES}

1) A. Azushima: The 148th Symp. for Plastic Working in JSTP, Tokyo Univ., Tokyo, (1992), 1.

2) K. Kitamura: Proc. of 30th Conf. in JSTP, Aichi-Ken Chusho Kigyo Center, Nagoya, Japan, (1979), 81

3) S. Fukuyama, M. Iwasaki and K. Nishimura: Proc. of 10th Spring Conf. in JSTP, Electrical Communication University, Johu-shi, Japan, (1979), 383.

4) H. Tamura: Proc of 10 th Conf. in JSTP, Electrical Communication University, Johu-shi, Japan, (1979), 387.

5) F. P. Valkenburg: The 4th Int. Steel Rolling Conf. at IRSID, Deauville, France, (1987), E51.1-E51.8.

6) Handbook of Iron and Steel, ed by ISIJ, Maruzen, Tokyo, (1983) 211.

7) J. Kim: J. Korean Soc. Lubr. Eng., 5 (1989), 21.

8) V. Ginzburg: Steel-Rolling Technology, Theory and Practice, Marcel Dekker Inc., New York, USA, (1989), 328.

9) D. R. Bland and J. Ford: Proc. I. Mech. E., 158, (1948), 174.

10) T. Sakurai: J. Jpn. Soc. Lubr. Eng. (in Japanese), 24 (1979), 416.

I1) J. Kihara, H. Nagamori, H. Matsuda and Y. Nakagawa: Int. Symp. for Metalworking Lubrication, ASME, San Francisco, USA, (1980), 171.

12) M. Kawamura, F. Kenji and N. Kiyoshi: J. Jpn. Soc. Lubr. Eng. (in Japanese), 25 (1980), 621. 